\title{
Student teachers' conceptions of curriculum: Toward an understanding of language-teacher development
}

Alister Cumming

\footnotetext{
Programmes for the education of second language teachers necessarily base themselves on conceptions of what learning to be a teacher entails. But surprisingly little study has been devoted to understanding the processes by which second language teachers actually develop their knowledge, or to defining what such knowledge consists of. This paper approaches this issue through a content analysis of data on one aspect of student teachers' professional knowledge: their conceptions of curriculum decision making. Different rep-

\begin{abstract}
ranging from schemata which appear inadequately developed to those which seem sufficient to guide curriculum decision-making effectively. Implications are drawn for the education and development of second language teachers, as well as further research in this area. It is argued that current "input-output" models of teacher education can be augmented by "developmental learning" models, if further understanding of language teachers' professional knowledge is obtained.
\end{abstract} resentations of this knowledge emerge,

Stern (1983) has observed that the models which have guided the education of second language teachers are mostly "input-output" specifications. They specify inputs, such as a knowledge of linguistics, language acquisition, pedagogical techniques, or relevant social conditions (see Corder 1968). Would-be teachers study such disciplines, and then are expected to apply the knowledge they have obtained (as outputs) to their teaching. This approach rarely functions to the full satisfaction of those involved, though student teachers evidently obtain a foundation of relevant information (Sukiwat and Smith 1981).

Conceptually, this model is less than adequate because it does not define how the inputs actually develop into achievements; it is a "black box" model without a learning theory. The upshot is that we know surprisingly little about how student teachers of second languages develop their knowledge. Nor are we able to base programmes of teacher education firmly on developmental models - of the kind that are widely advocated for learners of language or other disciplines (Case and Bereiter 1984).

Perhaps the most widespread criticism of input-output models for teacher education is that they leave a gap between educational theory and 
teaching practice. Knowledge gained from academic studies is theoretical in nature, distanced from the practical matters at hand in classroom instruction. Linguists, psychologists, and sociologists properly maintain the academic qualities of their disciplines, while student teachers study them. But, student teachers typically want (and need) to know how to practice language teaching. They perceive they require a kind of procedural (and not so much declarative) knowledge which will enable them to do the work of teaching effectively. This problem is analogous to the learning driver, who rather than practising to drive a car might be instructed in transportation economics, automobile mechanics, and map-reading. Though somewhat relevant, such knowledge does not foster learning which models the desired outcomes-be it driving or teaching. Hence, as many student teachers observe, their studies may appear inefficient or intangible.

Recent studies of language-teacher education have not really addressed this problem. Instead, they have concentrated on refining our definitions of the expected results (i.e. outputs) of teacher education. Some definitions specify the functions that language teachers can expect to perform (Yalden 1983, Hebert 1987). Others chart the kinds of decisions which language teachers might learn to deal with (Brumfit 1983, Brumfit and Rossner 1982). Still others indicate how language teachers' development interacts with institutional conditions and constraints (Kennedy 1987). Some derive models of effective teaching performance from psycholinguistic research on language learning (Lightbown 1986, Chaudron 1988). These definitions relate to research which has begun (1) to describe the characteristics of effective language teaching performance (Allen, Spada and Fröhlich 1984, Chaudron 1988, Gayle 1984, Wong-Fillmore 1985) or (2) to analyze how language teachers construe the specific problems they see as most central to their work (Johns 1981, Cumming 1984).

These definitions and research have clarified some of the goals of language-teacher education. At best, they facilitate a kind of means-ends analysis, guiding teacher educators toward a clearer sense of the appropriate instructional behaviours to foster in student teachers. It is recognized that the purposes of language-teacher education need to be based on more accurate descriptions of what student teachers have to do in their future teaching. But the perplexing problem remains of how the knowledge gained from teacher education actually "coheres" in the minds of student teachers (Brumfit 1983). What knowledge do student teachers gain from their studies? How do they conceptualize and integrate this knowledge? How do they apply it to their teaching? Without an understanding of these issues, how can we know what teacher education is doing? Or how it might be improved? 


\section{Some Emerging Conceptions of Curriculum Decision Making}

The present paper addresses some of these questions in a preliminary way, taking an exploratory look into the black box of language-teacher development. This provides an initial glimpse at the kinds of information that more thorough research might attempt to address in assessing teachers' developing knowledge. Its results are suggestive, rather than conclusive, indicating how a more comprehensive portrayal of student teacher's knowledge might be obtained in more extensive study, such as could serve as a basis for developmental models of language-teacher education-to augment the existing input-output models. The data assessed are of the conceptions of ESL curriculum decision making displayed by a small number of student teachers. Schematic representations of these conceptions were sought in order to obtain a relatively holistic portrayal of the student teachers' thinking about one aspect of language instruction ${ }^{1}$.

Thirty-seven pre-service teachers of ESL at a Canadian university were each asked to prepare a schematic chart outlining the curriculum decisions they would consider to be most important in teaching an ESL course. This task was a final assignment in a course on ESL curriculum, which had dealt with issues of course design, implementation, and evaluation, as in Dubin and Olshtain (1986). Instructions were that participants should prepare a schematic chart which brings together their knowledge of curriculum in a way that they could see as personally useful in their future teaching. Along with the chart, the student teachers were asked to submit a few pages of written text explaining how they would use the chart in ESL teaching ${ }^{2}$. The teachers were completing full-time programmes leading to a Bachelor of Education or Teaching Certificate. Most had small amounts of pedagogical experience through practica, tutoring, or teaching one or two courses.

A content analysis of these charts was done, itemizing the principal kinds of schematic representations which emerged. This analysis is highly interpretive. No efforts were made to test the interpretations against the student teachers' instructional performance. Nor was there comparable data available on expert or experienced teachers' representations of this problem, aside from that proposed by curriculum theories (see Miller and Seller 1985). Qualities of the schematic representations were assessed on the basis of whether or not they displayed knowledge which appears sufficient to guide curriculum decision-making in an ESL course. Could the representations be used practically by a teacher to manage the range of curriculum decisions usually encountered in teaching an ESL course?

Among the various schemata which were produced, three kinds of representations appeared sufficient to direct curriculum decision making effectively (Figures 8, 9, 10 below). In general, however, the student 
teachers produced representations with obvious (but revealing) shortcomings. These shortcomings were of three kinds (Figures 1 to 7 below), reflecting problems in the integration of knowledge common to the formative thinking of student teachers: disjunctive representations, disproportionate representations, and disparate representations.

\section{Disjunctive Representations}

The majority of the schematic charts represented ESL curriculum through obvious disjunctures between elements. In these cases, knowledge about curriculum appeared fragmented, in such a way that it would be difficult for teachers (using such models) to integrate their thinking about different aspects of curriculum in order to make instructional decisions.

The most common of these representations showed a distinct split between elements grouped as practice and those considered to constitute theory (as in Figure 1). Theory-based elements were derived from student teachers' studies of academic disciplines, whereas practice-based elements depicted a variety of instructional functions. Theoretical issues included ideas on language learning, accounting for the social context of a course or institution, or functions of language to be used after course completion. Practical issues dealt with topics like placement testing, student tasks, or evaluation of achievement. These two categories were visibly demarcated as separate conceptual units or levels, with no apparent means for them to be integrated in teaching practice. These representations displayed, quite vividly, the oft-cited divisions between theory and practice characteristic of teacher education.

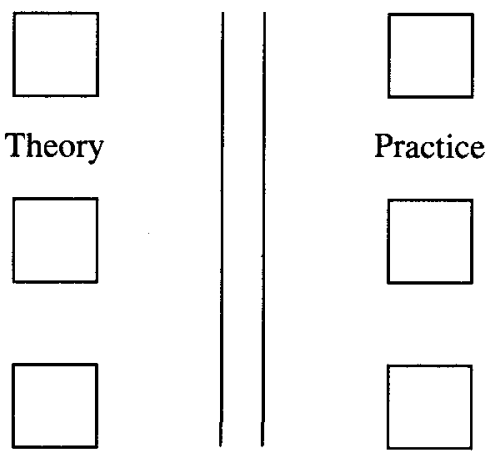

Figure 1: Theory/Practice Disjuncture

A second kind of disjunctive representation depicted curriculum decisions as one fixed sequence comprising totally separate stages (as in Figure 
2). These stages were conceived to follow one another, without any apparent means for relating decisions in the separate phases. Most of these schemata envisioned an initial phase of needs assessment, a brief period of course planning, the learning activities considered to make up the implementation of a course, and a final step of evaluating student outcomes. These representations resembled a reductive version of Tyler's well-known framework of curriculum planning-with the obvious flaw of each phase being conceptually unrelated to other phases, and hence no possibilities for curriculum integration, development or refinement.

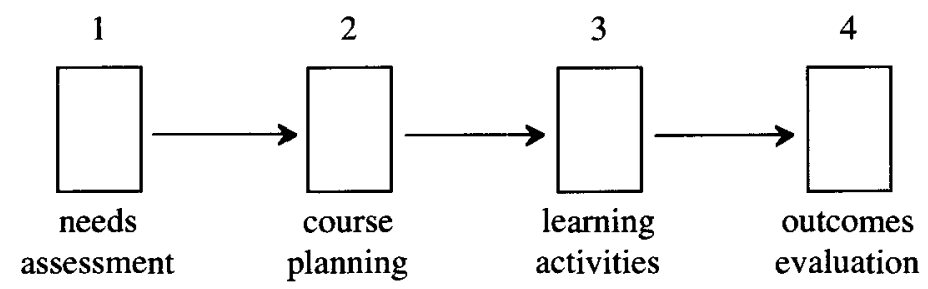

Figure 2: Separate Stages Disjuncture

\section{Disproportionate Representations}

A variety of the schematic charts placed disproportionate emphases on one aspect of curriculum decision making. These representations appeared unbalanced, putting inordinate value on certain elements, while diminishing the value of other ones.

Figure 3 shows how several of the schemata put exaggerated values on theories of language, learning or society-to the point that concepts of instructional practice were overshadowed. Instruction appeared to derive from academic disciplines, rather than concerns with real learners, content, or contexts.

Theories

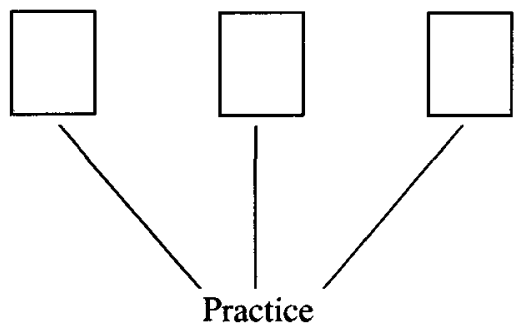

Figure 3: Disproportionate Emphasis on Foundation Theories 
A similar, but converse, representation placed a disproportionate emphasis on teaching practices (see Figure 4). In these cases, certain beliefs about classroom instruction were accredited with so much importance that people were led to quite questionable theorizing. For example, the priority put on one instructional procedure implied views of language or learning which may have been indefensible (or even bizarre) in real contexts. One person proposed that a full year of ESL study should consist only of "jigsaw" tasks, following the notion that, in her experience, students enjoy performing these activities more than other tasks. The criteria of "student enjoyment" and "instructional ease" overrode other considerations in this instance.

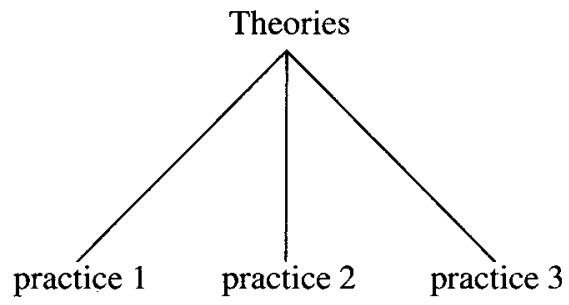

Figure 4: Disproportionate Emphasis on Teaching Practices

Other forms of disproportionate representations of curriculum were also presented in respect to classroom roles. In one case (see Figure 5) a schema was drawn to show the role of teacher as central to all curriculum decisions-to the point of neglecting student, institutional, or contextual considerations. Curriculum was depicted to exist in order to serve teacher development, and little else.

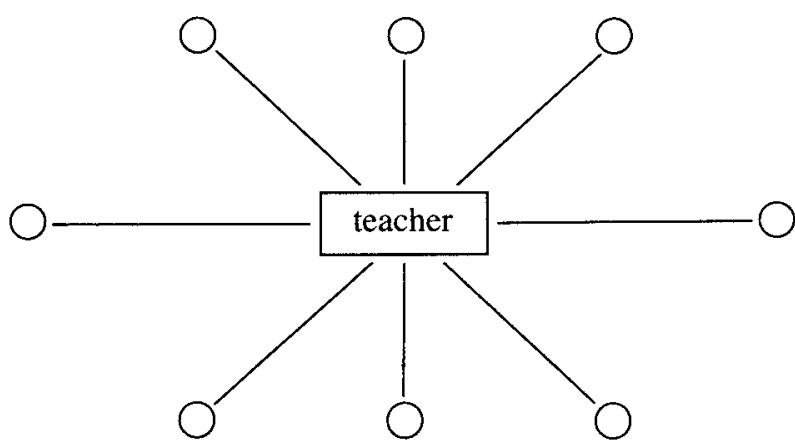

Figure 5: Disproportionate Emphasis on Teachers' Role 
A similar confusion about roles was evident in another representation which put "the learner" at the centre of curriculum decision making, but treated the learner conspicuously as a singular entity (as in Figure 6). Students were conceived to have absolutely identical characteristics, with no individual differences, purposes, or backgrounds. Curriculum decisions were said to derive from considerations of the "needs of the learner". But only one, absolutely-defined set of decisions was developed to account for this.

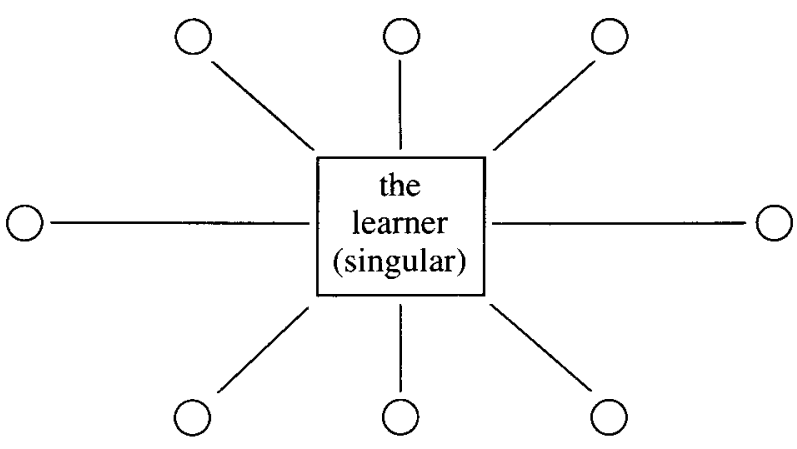

Figure 6: Disproportionate Emphasis on Learners' Similarities

\section{Disparate Representations}

The least well-developed of the representations were a few where curriculum decisions were treated as completely isolated events (see Figure 7). These showed separate decisions without any interrelations, sequences, or purposes. In these conceptions, there did not appear to be a coherent conception of curriculum decision making at all. Instead, fragmented actions were portrayed in seemingly random order. These mainly focussed on instructional functions, such as presenting lessons, evaluating student performance, or assessing textbooks. None of these functions was linked to the others, however, in any productive way.

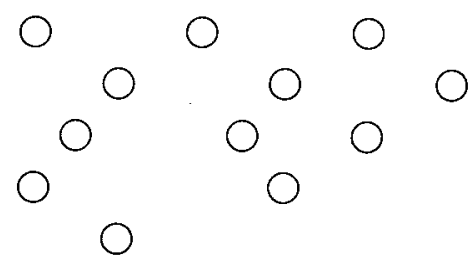

Figure 7: Disparate Knowledge 


\section{Representations Sufficient to Guide Decision Making}

Several of the schemata showed much fuller representations of curriculum decision making. These representations appeared sufficient to guide language instruction in a comprehensive and effective way, taking into account the complexity, interrelatedness, and importance of curriculum elements. At the same time, they displayed a framework which highlighted, and facilitated, on-going, interactive processes of decision making. The three representations of this kind may be complementary or alternative ways of portraying comparable perspectives. It is worth noting that these representations were prepared by student teachers who, in their written texts, also demonstrated a much deeper knowledge of how they would proceed in language teaching.

Two representations took the form of frameworks (see Figures 8 and 9) where a large range of options were itemized within interconnected categories accounting for the major aspects of an ESL curriculum. One of these representations placed learning options at the centre of the framework, while the other showed a series of interconnected levels of decision making which began with institutional, philosophical, and sociocontextual variables.

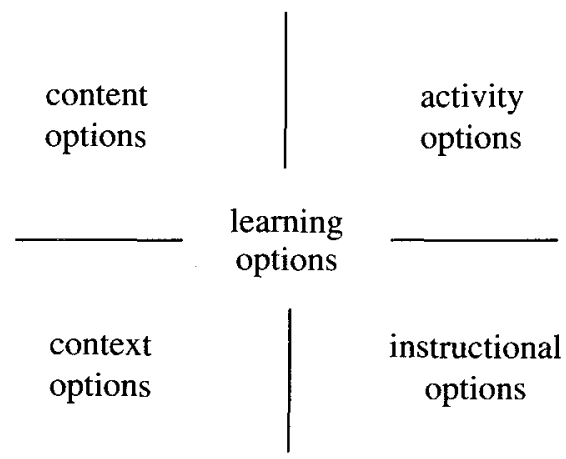

Figure 8: One Representation of Interconnecting Options

The third representation of this kind took the form of a decision-making tree (see Figure 10). Options like those in Figures 8 and 9 were itemized, but as alternatives choices following a progressive sequence of categorical considerations. Interestingly, this representation was not purely hierarchical, in a way that would have fixed decisions irrevocably. Rather, it consisted of nested hierarchies which would permit the interrelationship of decisions at different nodes in the framework. It thus took a "hetrarchical" form, such as research by Hayes-Roth and Hayes-Roth (1979) suggests may be the most accurate representation of cognitive planning. 


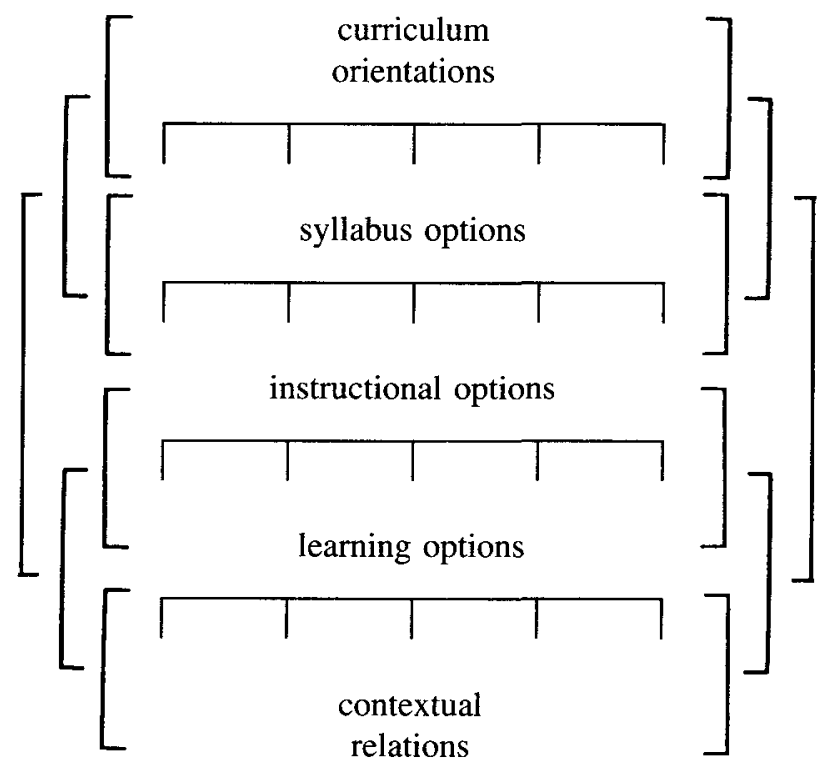

Figure 9: A Second Representation of Interconnecting Options

\section{Discussion}

These schematic representations display graphically how a small group of student teachers appeared to conceive of ESL curricula. The data are suggestive of the "mental models" (Johnson-Laird 1983) of pre-service language teachers, pointing out notions which could be assessed more fully in studies of student teachers actually teaching or otherwise developing their professional expertise. The schemata reduce the knowledge of student teachers considerably, only providing images of how this knowledge may be represented mentally. As such, they may offer little more than a partial glimpse at the actual knowledge which student teachers may

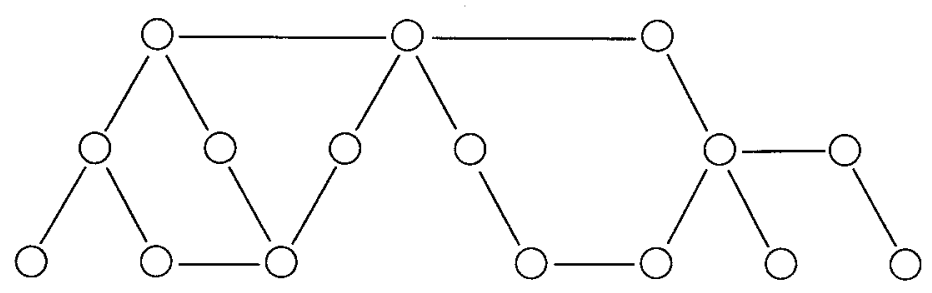

Figure 10: Hetrarchical Decision Making 
have and use when they teach. Much of this knowledge may not be consciously retrievable or amenable to schematic representation. Moreover, these schemata do not address other aspects central to instructional functions, such as classroom management routines, lesson planning and analysis, specialized discourse patterns, administrative interactions, or student relations and assessment.

For the most part, the representations depict the difficulties that these student teachers had integrating the various complex aspects of curriculum into a conceptual whole. Few of the representations appeared to be sufficient to guide curriculum decision making effectively. This is seemingly for the reason that the individual student teachers had not yet developed full mental representations of this problem. The variety of representations elicited suggests that teacher education should be far more concerned with how teachers" knowledge "coheres" within the minds of individuals (Brumfit 1983). Rather than cohering in common ways, knowledge about ESL curriculum seems, in fact, to be integrated for student teachers in quite different ways and to different degrees. Individual differences seem to abound, rather than to be an exception, indicating that individual development needs to be considered more extensively than conventional input-output models of teacher education may allow.

One way of interpreting these data is to see them as displaying constraints on information-processing capacities and knowledge structures. Student teachers are developing a knowledge of curriculum, from the instructional viewpoint of responsibility for planning, implementing and assessing ESL courses. The sheer quantity of factors to take into account in this process, and to integrate conceptually, poses difficulties. Since these pre-service teachers had (by definition) little experience handling such matters, it appears natural to expect disjunctive, disproportionate, or disparate representations of the problem at hand. These are characteristic of learning in a new domain (Case and Bereiter 1984, Keil 1981, JohnsonLaird 1983).

What routes could we expect these individuals to take to develop the professional knowledge they might need to make effective curriculum decisions in ESL teaching? It is worth asking this question in view of its implications for the organization of the initial education of language teachers. Since these student teachers were just completing a course in ESL curriculum (and a programme for teacher certification), it is obvious that this "input" from an academic course is not enough, by itself, to expect a full professional knowledge to develop for most individuals. For many, there is an obvious gap between the "input" of teacher education and the requisite "outputs" needed for effective teaching performance. How may this gap be filled? 


\section{Training models}

It might be suggested that academic study of education is inappropriate to develop the practical skills needed for teaching. A training model for language-teacher preparation could be seen to address this issue more explicitly, as it does in many college, continuing education, or in-house professional development programmes. Concrete but simple outcomes are aimed for, based on the acquisition of instructional methodologies. These might involve demonstrations of teaching techniques, exercises in lessonplanning and materials preparation, and simulated practice teaching. But this approach has obvious shortcomings, unless it is viewed simply as an initial orientation, the provision of helpful tips, or a means of introducing field-specific terminology. This is especially obvious for the complex knowledge about curriculum decision making assessed in the present study.

One shortcoming with a training approach is that the methodology of second language teaching varies situationally (Burnaby 1987, Strevens 1980), culturally (Cumming 1986, Lewis and Massad 1975) and historically (Breen 1987, Howatt 1984). Teachers trained in one period, institution, or situation may find that instructional approaches differ significantly in situations where they later work. These may involve entirely different views of classroom relations, syllabus organization, and instructional content. A training model of teacher education is relative to one time and place, readily outmoded, and constantly in need of further "inputs" to remain up-to-date (Cropley and Dave 1978).

More seriously, most training programmes are limited versions of an input-output model of teacher education, but they are more severely restricted in their inputs. Teachers are not educated; they are shown how to follow a limited number of prescribed techniques. As many have clearly argued (Peters 1973, Houle 1983, Larson-Freeman 1983), training (unlike education) does not aim to foster abilities to make intelligent choices, plan relevant courses of action, evaluate central elements, or reconceptualize new knowledge. (Though these are functions that one would, ideally, like teachers to be able to perform well.) Put in another way, student teachers following a narrowly defined training programme are not "empowered". They are tied to the restricted set of methodologies they are shown, yet have been given little ability to analyze, interpret broadly, relate to unexpected circumstances, or modify to suit unique circumstances. A narrow range of instructional skills cannot provide the adaptability needed for the diverse situations and roles in which second language teachers work internationally. It would also appear to be less than language teachers tend to expect of themselves as educated professionals (Altman 1980). 


\section{Higher education}

An alternative route to developing further knowledge about decision making in language curricula could be graduate studies. Many of the student teachers' representations showed a tendency toward the kinds of bimodal thinking which Collis and Biggs (1983) claim is characteristic of students completing Bachelor's degrees. There tended to be a focus on two separate elements (often labelled "theory" and "practice"), without common means, principles or criteria to integrate them. As Collis and Biggs' data suggest, further academic studies, perhaps at the Masters level, would typically provide for the intellectual formation needed to deal with such problems conceptually. A related proposal could be the introduction of schema for curriculum decision making, as in Mohan's (1986) "knowledge framework", into programmes of teacher education. Though the introduction of such frameworks into education programmes is open to the reductions of "training" models noted above, it does provide a concrete basis for student teachers to begin to conceive of the complexity of curriculum decision making in language education. Analyses of student teachers using such frameworks need to be done to see how they shape their perceptions of curriculum decision making or whether they can counter some of the conceptual shortcomings cited above.

\section{Practice teaching}

It may be more realistic to consider that knowledge about teaching derives from practice teaching. Learning to deal with the problems of curriculum organization inevitably occur through experience teaching. Beginning teachers would, necessarily, have to formulate fuller representations of curriculum decision making as part of their first jobs as teachers-learning, experientially, to deal with it more effectively. Presumably, this is the route that most of these student teachers will follow. However, this is an unnecessarily ad-hoc approach to learning, one that denies professional responsibility and constrains educational effectiveness.

For this reason, many programmes of language teacher education place the burden for functional learning-learning to perform as a teacher-on some form of teaching practicum. This is usually tagged onto the end of a much lengthier period of academic course work, with the expectation that an experience in a school will somehow "bridge" theory and practice. As Richards and Crookes (1988) point out, however, in a recent survey, the purposes and substance of practice-teaching experiences for TESL vary greatly from institution to institution, giving the impression of being ill-defined in view of any requisite content. Neither their effects nor their conditions are well understood from the viewpoint of student teachers' learning. Similar variability probably occurs in the academic components 
of teacher education programmes as well, making uniform "outcomes" of practica an unlikely possibility.

Though it is clear that practicum experiences lead student teachers from the idealism of academic knowledge to some familiarity with the practical realities (and complexities) of school life (Tabachnik 1980), it is not at all clear how much they actually contribute to the knowledge integral to language teaching (Stern 1983). Many practicum experiences appear to be too brief and too constrained to foster the kinds of knowledge which teachers come to possess after years of experience (Cropley and Dave 1978, Fullan and Connelly 1987, Rubin 1978, Yinger 1987).

\section{Toward a Developmental Learning Model}

The conventional input-output models guiding language teacher education are not necessarily inaccurate or inappropriate. But they do appear to be inadequate, in their neglect of learning processes. Like other learning theories based on behaviourist principles, external inputs (or reinforcers) are emphasized; the emerging knowledge of learners is not taken into account in the design of instruction (Case and Bereiter 1984). Student teachers, like learners in other domains, may interpret, conceptualize, and act on what is taught to them in radically different or ineffective ways. There is, therefore, not a sufficient basis on which to ensure that (or whether) learning is achieved-short of outcomes testing, which is an evaluation procedure, not an educational process ${ }^{3}$. To fill out the obvious gaps between the conventional "inputs" and "outputs" of language teachers' education requires a more substantial understanding of how student teachers develop their knowledge, and what that knowledge consists of.

To enhance existing models of teacher education it is necessary to understand more accurately the processes of learning to be a second language teacher. We need to look inside more deeply into the "black box" of teacher development to see what learning takes place there and how it occurs. An understanding from two perspectives is needed. One is phenomenological or cognitive; the other is developmental. The phenomenological or cognitive issues concern an awareness of the conceptions that student teachers have of language instruction (see Clark and Peterson 1986). How do they conceive of the various phenomena of language teaching? What terms, images or constructs do they use to think about them? How do they consider putting this knowledge into practice? How do they interpret the problems of teaching a second language, and what do they see and use as means of solving these problems?

A developmental perspective is needed to know how student teachers enhance their conceptions of language instruction with experience or increased knowledge. Representative contrasts could be obtained by assess- 
ing how the thinking and practices of (1) student language teachers differ from the conceptions and actions of (2) experienced, effective teachers. Alternatively, developing conceptions and behaviours of student teachers might be charted longitudinally in case studies-to ascertain the changes they undergo over time. Additionally, learning to teach a second language needs to be assessed in relation to key "inputs" which effectively foster new learning (see Fullan and Connelly 1987). How does this happen? What conditions best foster this development? What stages or progressions do people go through? What are the salient issues? Why?

A substantial body of research on teachers' knowledge has, recently, been addressing these issues in education at large. Detailed case studies of teachers at work have established that special kinds of practical knowledge inform and guide their actions (Clandinin 1986, Elbaz 1983, Munby 1982). Detailed studies of particular pedagogical issues have started to document how this practical knowledge develops through experiences, education and reflection (Ball and Feiman-Nemser 1988, Tabachnik 1980, Yinger 1987). Observational studies suggest that much of this practical knowledge focuses on organizing routines to create efficient classroom learning environments (Doyle 1983, Leinhardt, Weidman and Hammond 1987). Similarly, studies of teachers' thinking show how their attention is directed, in very complex ways, at planning and assessing classroom activities, curriculum content, and student achievement (Andreson, Barrett, Powell and Wienke 1985, Burns 1984, Clark and Peterson 1986, Cumming 1988, McGregor and Meiers 1983).

Are these processes of using and learning specialized practical knowledge common to developing language teachers as well? Presumably, they are, in a general way. But in the absence of research of this kind on second language teachers, it is difficult to say to what extent or precisely how. Existing models for the education of second language teachers have stressed the uniqueness of their professional functions, citing the special qualities of discourse and learning desirable in second language classrooms (Chaudron 1988, Hebert 1987, Lightbown 1986, Yalden 1983), as well as the diverse unconventional roles, such as community leadership (Handscombe and Handscombe 1983), which second language instructors are commonly called upon to perform.

However, it is doubtful if a common ground of practical knowledge is shared, in an absolute sense, by individual teachers in the same field. Case studies comparing subject-matter teachers have stressed the fundamental differences between their thinking and approaches to instruction, even within common disciplines in a single school (Elbaz 1983, Langer and Applebee 1987). The kinds of practical knowledge which teachers use in teaching appear to exist largely in very personal terms, based on unique experiences, individual conceptions, and their interactions with local con- 
texts. It tends to have a personal significance which differs from the prescribed models of educational theory (Clark and Peterson 1986, Joyce and Weil 1980).

It is obvious that much further research on this topic would be profitable for language-teacher education. This could explore alternative ways of thinking about teachers' knowledge (Egan 1988), the conditions which best support teacher development (Fullan and Connelly 1987), naturalistic portraits of teacher performance (Clandinin 1986, Cumming 1989), and study of the cognitive processes which teachers use to guide their work (Clark 1988). If language teacher education is to have a substantive basis, grounded in an understanding of the learning it aims to produce, then much, much more needs to be done to document, analyze, and assess what that learning actually is.

\section{REFERENCES}

Andresen, L., E. Barrett, J. Powell, and C. Wienke (1985). Planning and monitoring courses: University teachers reflect on their teaching. Instructional Science $13,305-328$.

Allen, J.P.B., M. Fröhlich, and N. Spada. (1984). The communicative orientation of language teaching. In J. Handscombe, R.A. Orem and B.P. Taylor (Eds.) On TESOL '83. Washington, D.C.: TESOL.

Altman, H. (1980). On the need for a profession of language teachers. Canadian Modern Language Review 36(3), 397-402.

Ball, D.L. and S. Feiman-Nemser. (1988). Using textbooks and teachers' guides: A dilemma for beginning teachers and teacher educators. Curriculum Inquiry $18(4), 401-423$.

Breen, M.P. (1987). Contemporary paradigms in syllabus design. Language Teaching 20(2-3), 81-92, 157-174.

Brumfit, C. (1983). Creating coherence in ELT teacher training. In R.R. Jordan (Ed.) Case Studies in ELT. London: Collins.

Brumfit, C. and R. Rossner. (1982). The decision pyramid and teacher training for ELT. ELT Journal 36(4), 226-231.

Burnaby, B. (1987). Language for native, ethnic, or recent immigrant groups: What's the difference? TESL Canada Journal 4(2), 9-27.

Burns, R. (1984). The process and content of teaching: A conceptual framework. In D.W. Ryan and L.W. Anderson (Eds.) Rethinking Research on Teaching. Oxford: Pergamon.

Case, R. and C. Bereiter. (1984). From behaviorism to cognitive behaviorism to cognitive development. Instructional Science 13(2), 141-158. 
Chaudron, C. (1988). Second Language Classrooms. New York: Cambridge University Press.

Clandinin, J. (1986). Classroom Practice: Teacher images in action. London: Falmer Press.

Clandinin, J. and F.M. Connelly. (1984). Teachers' personal practical knowledge. In R. Halkes and J.K. Olson (Eds.) Teacher Thinking: A new perspective on persistent problems in education. Heirewig, Netherlands: Swets.

Clark, C.M. (1988). Asking the right questions about teacher preparation: Contributions of research on teacher thinking. Educational Researcher 17(2), 5-12.

Clark, C.M. and P.L. Peterson. (1986). Teachers' thought processes. In M. Wittrock (Ed.) Handbook of Research on Teaching. 3rd. ed. New York: Macmillan.

Collins, K. and J. Biggs. (1983). Matriculation, degree structures, and levels of student thinking. Australian Journal of Education 27(2), 151-163.

Corder, S.P. (1968). Advanced study and the experienced language teacher. In G.E. Perren (Ed.) Teachers of English as a Second Language: Their training and preparation. Cambridge: Cambridge University Press.

Cropley, A.J. and R.H. Dave. (1978). Lifelong Education and the Training of Teachers. Oxford: Pergamon.

Cumming, A. (1984). A problem-centred approach to in-service training and language program development. TESL Manitoba Journal 1(1) 38-45.

Cumming, A. (1986). Evaluations and developments of foreign language education in China. Canadian and International Education 16(1), 211-220.

Cumming, A. (1988). Change, organization and achievement: Teachers' concerns in implementing a computer learning environment. Journal of Educational Technology Systems 17(2), 141-163.

Cumming, A. (1989). The orchestration of ESL performance. Paper presented at the annual convention of B.C. TEAL, Vancouver.

Doyle, W. (1983). Academic work. Review of Educational Research 53(1), 159 199.

Dubin, F. and E. Olshtain. (1986). Course Design: Developing programs and materials for language teaching. Cambridge: Cambridge University Press.

Egan, K. (1988). Metaphors in collision: Objectives, assembly lines, and stories. Curriculum Inquiry 18(1), 63-86.

Elbaz, E. (1983). Teacher Thinking: A study of practical knowledge. New York: Nichols.

Fullan, M. and F.M. Connelly. (1987). Teacher Education in Ontario: Current practice and options for the future. Toronto: Ontario Ministry of Education.

Gayle, G. (1984). Effective second-language teaching styles. Canadian Modern Language Review 40(5), 525-541. 
Handscombe, J. and R. Handscombe. (1983). The leadership component in the professional development of ESL teachers. In J. Alatis, H.H. Stern and P. Strevens (Eds.) Applied Linguistics and the Preparation of Second Language Teachers: Toward a rationale. Washington, D.C.: Georgetown University Press.

Hayes-Roth, J.R. and F. Hayes-Roth. (1979). A cognitive model of planning. Cognitive Science 3(3), 275-310.

Hebert, Y. (1987). Towards a conceptualization of teacher education for French language schools and programs in western Canada. Canadian Modern Language Review 43(4), 643-663.

Houle, C.O. (1983). Possible futures. In M.R. Stern (Ed.) Power and Conflict in Continuing Professional Education. Belmont, California: Wadsworth.

Howatt, A. (1984). A History of English Language Teaching. Oxford: Oxford University Press.

Keil, F.C. (1981). Constraints on knowledge and cognitive development. Psychological Review 88(3), 197-227.

Kennedy, C. (1987). Innovation for change: Teacher development and innovation. ELT Journal 41(3), 163-170.

Johns, T.M. (1981). Some problems of a world-wide profession. ELT Documents 112. London: British Council.

Johnson-Laird, P. (1983). Mental Models. Cambridge, Mass.: Harvard University Press.

Joyce, B. and M. Weil. (1980). Models of Teaching. 2nd ed. Englewood Cliffs, N.J.: Prentice-Hall.

Langer, J. and A. Applebee. (1987). How Writing Shapes Thinking: A study of teaching and learning. Urbana, Illinois: National Council of Teachers of English.

Larson-Freeman, D. (1983). Training teachers or educating a teacher. In J. Alatis, H.H. Stern and P. Strevens (Eds.) Applied Linguistics and the Preparation of Second Language Teachers: Toward a rationale. Washington, D.C.: Georgetown University Press.

Leinhardt, G., C. Weidman, and K.M. Hammond. (1987). Introduction and integration of classroom routines by expert teachers. Curriculum Inquiry 17(2), 135-176.

Lewis, E. and C. Massad. (1975). The teaching of English as a Foreign Language in Ten Countries: International studies in evaluation IV. New York: John Wiley and Sons.

Lightbown, P. (1986). What's an ESL teacher good for? TESL Canada Journal, special issue $1,1-15$. 
McGregor, R. and C. Meiers. (1983). English Teaching in Practice: Talking with teachers. Sydney: St. Clair Press.

Miller, J. and W. Seller. (1985). Curriculum: Perspectives and practice. London: Longman.

Mohan, B. (1986). Language and Content, Reading, Mass.: Addison-Wesley.

Munby, H. (1982). The place of teachers' beliefs in research on teacher thinking and decision making, and an altenative methodology. Instructional Science 11, 201-225.

Palmer, H. (1917) (reissue 1968). The Scientific Study and Teaching of Languages. London: Oxford University Press.

Peters, R.S. (1973). The aims of education. In The Philosophy of Education. London: Routledge and Kegan Paul.

Richards, J. and G. Crookes. (1988). The practicum in TESOL. TESOL Quarterly 22(1), 9-27.

Rubin, L. (Ed.) 1978. The In-service Education of Teachers: Trends, processes and prescriptions. Boston: Allyn and Bacon.

Stern, H.H. (1983). Language teacher education. In J. Alatis, H.H. Stern and P. Strevens (Eds.) Applied Linguistics and the Preparation of Second Language Teachers: Toward a rationale. Washington, D.C.: Georgetown University Press.

Strevens, P. (1980). Teaching English as an International Language. Oxford: Pergamon.

Sukiwat, M. and L.E. Smith. (1981). Are M.A. teacher education programs getting the job done? In J.C. Fisher, M.A. Clarke, and J. Schachter (Eds.) On TESOL '80: Building bridges. Washington: TESOL.

Tabachnik, B.R. (1980). Intern-teacher roles: Illusion, disillusion and reality. Journal of Education 162 (1), 122-137.

Wong-Fillmore, L. (1985). When does teacher talk work as input? In S. Gass and C. Madden (Eds.) Input in Second Language Acquisition research. Rowley, Mass.: Newbury House.

Yalden, J. (1983). Training needs in the '80s: The ESL teacher in Canada. Canadian Modern Language Review. 40(1), 19-22.

Yinger, R.J. (1987). Learning the language of practice. Curriculum Inquiry. 17(3), 293-318.

\section{NOTES}

1. Curriculum decision making has long been recognized as a central professional responsibility for second language teachers. Palmer (1917, p. 167), for instance, observes that "it is the teacher himself who has to consider what course will have to be pursued in different cases and to organize the programme best adapted to each particular end." 
2. Analyses of these written texts were not pursued, because the purposes of the study were directed at the more holistic representations reported here. These texts were referred to, however, in interpreting the schematic representations. The charts of the student teachers' schemata presented here are drawn to synthesize but closely resemble key features of those produced by the student teachers. However, they are not, of course, those actually produced by them. More thorough verbal data could have been obtained in this study, using elicitation techniques such as journal or autobiographical reports, interviews, narrative accounts, classroom observations, or think-aloud protocols (see studies of teachers' knowledge reviewed in the final section of this paper). But the purpose of the study was exploratory, aiming to establish the kinds of information to be collected in more detailed research (which is now under way).

3. This is an especially contentious issue in cases of student teachers who may "fail" a practicum. Has their educational program adequately prepared them for classroom practice? Or are complex personality or attitudinal traits being evaluated?

\section{THE AUTHOR}

Alister Cumming (Ph.D. Toronto) is Assistant Professor in the Department of Language Education at The University of British Columbia. His research interests are in writing in second languages, curriculum evaluation and development, and processes of thinking and learning in ESL instruction. 